\title{
ATRIBUTOS EDAFOAMBIENTAIS E PARÂMETROS DENDROMÉTRICOS DE PLANTIOS DE EUCALIPTO EM UMA TOPOSSEQÜÊNCIA NO CAMPUS DA UFRRJ, SEROPÉDICA (RJ) ${ }^{1}$
}

\author{
EDAPHOENVIRONMENTAL ATTRIBUTES AND DENDROMETRIC PARAMETERS IN \\ EUCALYPTS SITES IN A TOPOSSEQUENCE AT UFRRJ CAMPUS, SEROPÉDICA (RJ)
}

Thaís Andrade Corrêa Neto ${ }^{2}$ Lúcia Helena Cunha dos Anjos ${ }^{3}$ Marcos Gervasio Pereira ${ }^{4}$ Hugo Barbosa Amorim ${ }^{5}$ Carlos Felipe de Siqueira Jaccoud ${ }^{6}$

\section{RESUMO}

Este estudo relaciona atributos edafoambientais e parâmetros dendrométricos de plantios de Eucalyptus urophylla. O experimento foi realizado em talhões comerciais da mesma idade, no campus da UFRRJ em Seropédica (RJ), em três sítios selecionados em posições topográficas distintas, no terço superior (TS), no terço médio (TM) e no terço inferior (TI) da encosta. Foram avaliados: atributos morfológicos, físicos e químicos dos perfis de solo; coletadas amostras nos talhões para avaliação do teor de nutrientes; e medidos parâmetros dendrométricos. Os sítios apresentam diferentes classes de solo, Argissolo VermelhoAmarelo, Argissolo Amarelo e Planossolo Háplico, dispostos do topo para o terço inferior da encosta respectivamente. Foram observadas diferenças significativas entre os sítios, quanto aos teores de nutrientes e outros atributos químicos, que se refletiram nos parâmetros dendrométricos. Os maiores valores de área basal foram observados em TS e TI, respectivamente, 4,11 e 4,64 $\mathrm{m}^{2} \mathrm{ha}^{-1}$. Os sítios onde os atributos edafoambientais mais influenciaram positivamente os parâmetros dendrométricos do Eucalyptus urophylla foram o TS e o TI.

Palavras-chave: Propriedades edáficas; plantio homogêneo; silvicultura.

\section{ABSTRACT}

This study relates soil and environmental attributes and dendrometric parameters of Eucalyptus urophylla plots. The experiment was set in eucalyptus sites for commercial production, of the same age, located in the UFRRJ campus, Seropédica municipality (RJ). Three sites were selected in different topographic positions of the landscape, summit (TS), back slope (TM), and foot slope (TI). Morphological, physical, and chemical soil attributes were evaluated; soil samples were taken from the plots for analyzing nutrient levels; and dendrometric parameters were measured. The sites showed different soil classes, RedYellow Ultisol, Yellow Ultisol, and Fragiudult (Planosols), placed from the summit to the foot slope positions, respectively. There were significant differences between the sites for the nutrient content and other chemical attributes, which reflected in the dendrometric parameters. The highest values of tree base area were observed in the TS and TI positions, of 4.11 and $4.64 \mathrm{~m}^{2} /$ ha, respectively. The sites where soil and environmental attributes favored most the dendrometric parameters of Eucaliptus urophylla were TS and TI.

Keywords: Soil properties; homogeneous plantation; forest production.

\section{INTRODUÇÃO}

A atividade de plantios florestais homogêneos para fins comerciais é uma atividade em rápida expansão no Brasil, em especial nas regiões Sul e Sudeste. A utilização predominantemente do gênero Eucalyptus, que possui elevado número de espécies e sua grande capacidade de adaptação às mais variadas condições ecológicas, leva à necessidade de estudos sobre a qualidade do ambiente nos plantios comerciais.

1. Parte da dissertação de Mestrado do primeiro autor apresentada ao Curso de Pós-Graduação em Agronomia/Ciência do Solo, do Instituto de Agronomia da Universidade Federal Rural do Rio de Janeiro.

2. Engenheira Agrônoma, Mestre em Ciências pelo Curso de Pós-Graduação em Agronomia/Ciência do Solo, Instituto de Agronomia, Universidade Federal Rural do Rio de Janeiro, BR 465, km 7, CEP 23890-000, Seropédica (RJ).

3. Engenheira Agrônoma, PhD., Professora Adjunta do Departamento de Solos, Instituto de Agronomia, Universidade Federal Rural do Rio de Janeiro, BR 465, km 7, CEP 23890-000, Seropédica (RJ). lanjos@ufrrj.br

4. Engenheiro Agrônomo, Dr., Professor Associado do Departamento de Solos, Instituto de Agronomia, Universidade Federal Rural do Rio de Janeiro, BR 465, km 7, CEP 23890-000, Seropédica (RJ). gervasio@ufrrj.br

5. Engenheiro Florestal, Dr., Professor Associado do Departamento de Silvicultura, Instituto de Florestas, Universidade Federal Rural do Rio de Janeiro, BR 465, km 7, CEP 23890-000, Seropédica (RJ).

6. Acadêmico do Curso de Graduação em Engenharia Florestal, Universidade Federal Rural do Rio de Janeiro, BR 465, km 7, CEP 23890-000, Seropédica (RJ).

Recebido para publicação em 26/04/2005 e aceito em 6/11/2006. 
Pela plasticidade da cultura do eucalipto e a grande diversidade de sítios onde são feitos os plantios, é importante relacionar as propriedades edáficas aos parâmetros de crescimento e produtividade da cultura (Corrêa Neto, 2004).

A escolha das espécies de eucalipto potencialmente aptas para o plantio no Brasil tem se baseado, primeiramente, em critérios climáticos. Embora segundo Spurr e Barnes (1980), dentro de um mesmo estrato climático, variações locais de topografia podem levar ao crescimento de ecótipos com exigências de água e nutrientes diferenciadas entre si. Para evidenciar a importância de outros aspectos, observa-se que algumas espécies e/ou procedências de eucalipto introduzidas em algumas regiões do Brasil, embora tivessem semelhança com os parâmetros climáticos das regiões de origem, não mostraram o crescimento desejado. Ainda, espécies e/ou procedências dissimilares quanto a condições climáticas, na Austrália e no Brasil, mostram uma boa adaptação (Barros e Novais, 1990).

Quanto aos diferentes domínios, plantios realizados no ambiente de Cerrado em Minas Gerais apresentaram menor altura quando comparados com ambientes de Mar de Morros e de Tabuleiros Costeiros, em Minas Gerais e no Espírito Santo. Os solos de Cerrado, em sua maioria Latossolos ou Argissolos, apresentam altas taxas de lixiviação de nutrientes, ao passo que são menos suscetíveis à erosão hídrica em função do relevo plano à suave ondulado. Os plantios em áreas de Mar de Morros apresentam valores maiores em altura que no Cerrado. No Mar de Morros as perdas de nutrientes nos diversos tipos de solos são intensas e sobretudo pela erosão hídrica, por causa do relevo mais acidentado. Os Latossolos Amarelos e Argissolos Amarelos do domínio de Tabuleiros Costeiros, em plantios no Espírito Santo, localizam-se em relevo plano a suave ondulado e possuem permeabilidade reduzida, assim a perda dos nutrientes por erosão e lixiviação é menor que nos outros dois ambientes, (Ferreira e Couto, 1981).

Bellote e Ferreira (1993) relacionaram os teores de nutrientes no solo com a produtividade do Eucalyptus grandis, aos 3 anos de idade, em 15 sítios florestais, no sstado de São Paulo (Mogi-Guaçú, Casa Branca, Itirapina, Itatinga e Angatuba). Os autores verificaram correlações positivas entre os teores de fósforo, potássio, magnésio e cálcio e a produtividade. Em estudo sobre ciclagem de nutrientes, em povoamentos de eucalipto na região Norte-Fluminense do RJ, Zaia e Gama-Rodrigues (2004) enfatizam a escolha de espécies com base na taxa de exportação relativa de nutrientes, para elevação do estoque de nutriente no sistema solo-planta, reduzindo a necessidade de adubação.

A elaboração de planos de manejo em plantios florestais requer informações sobre a espécie em estudo quanto ao volume e número de árvores, qualidade do estoque em termos de diâmetro, alturas, defeitos e a produtividade do estoque em crescimento. Deve-se avaliar também a capacidade produtiva do sítio florestal, quantificar a produção e o crescimento por unidade de área e fazer predições para o futuro (Machado e Figueiredo Filho, 2003).

A determinação da classe de produtividade dos plantios de eucalipto, pelos parâmetros como volume de madeira com casca e diâmetro à altura do peito (DAP), deve-se ser também relacionada aos atributos dos solos. O potencial da produção florestal de uma determinada localidade deve ser estabelecido em função de fatores ambientais e da produção do plantio florestal, permitindo a tomada de decisões adequadas tanto no sentido da escolha e adaptação de espécies como da produção econômica (Hosokawa, 1998).

Este estudo tem como objetivo relacionar atributos edafoambientais em diferentes sítios e sua influência em parâmetros dendrométricos de plantio de Eucalyptus urophylla, no campus da Universidade Federal Rural do Rio de Janeiro, Seropédica.

\section{MATERIAL E MÉTODOS}

O experimento foi realizado em plantios comerciais de Eucalyptus urophylla, com a mesma idade, instalados para produção de matéria-prima para carvão. Os plantios estão localizados em área da Universidade Federal Rural do Rio de Janeiro, no município de Seropédica (RJ), com relevo ondulado e suave-ondulado. Os três sítios de estudo foram selecionados em posições topográficas distintas, no terço superior (TS), no terço médio (TM) e no terço inferior (TI) da encosta. Os solos em cada sítio foram diferenciados quanto à classe, características do terreno e influência do lençol freático, e foi avaliada a produtividade do eucalipto em cada sitio.

Os talhões fazem parte do projeto Pró-Floresta III, convênio entre a UFRRJ e a empresa Saint- 
Gobain Canalização, instalado no período de dezembro de 2001 a janeiro de 2002. Cada área experimental possui 250 covas, e o espaçamento de plantio foi o de 5x2 m. Quanto ao histórico de uso da área, foram realizadas as seguintes práticas na implantação do plantio: subsolagem e adubação de pré-plantio com $240 \mathrm{~kg}$ ha $^{-1}$ da fórmula NPK (5-30-15), combate às formigas e aplicação de glifosato para controle de plantas espontâneas. Em 2003, como operações de manutenção, foram realizadas: gradagem e roçada mecânica, nas áreas de relevo suave-ondulado e plano, e roçada manual na área com relevo ondulado; combate às formigas; e adubação de cobertura com $100 \mathrm{~kg} \mathrm{ha}^{-1}$ da fórmula NPK (20-00-20).

Em cada um dos sítios, foram abertas trincheiras para descrição de perfis de solo, sendo avaliadas as seguintes propriedades morfológicas: profundidade dos horizontes, cor, textura expedita, estrutura, consistência, transição e classe de drenagem interna do solo, segundo critérios de Lemos e Santos (1996). Os perfis de solos foram caracterizados quanto aos seguintes atributos: composição granulométrica; carbono orgânico; pH em água; P assimilável; teores de Ca, Mg, K e Al extraíveis e acidez extraível. Partindo dessas análises, foram calculados os índices: grau de floculação; Soma de bases (Valor S); Capacidade de Troca Catiônica (Valor T); Saturação por bases (Valor V\%) e saturação por alumínio, para posterior classificação dos solos de acordo com o Sistema Brasileiro de Classificação de Solos (EMBRAPA, 1999).

Para a análise da fertilidade dos solos de cada sítio (TS, TM e TI), foram coletadas três amostras compostas, cada uma formada por dez amostras simples, nas profundidades de 0-20 e 20-40 cm. A amostragem de solo foi feita entre as linhas de plantio e entre as plantas.

As análises físicas e químicas, para a caracterização dos perfis e das amostras para fins de fertilidade, seguiram a metodologia da EMBRAPA (1997). Os resultados foram submetidos à análise de normalidade e ANOVA, sendo empregado o programa SAEG 5.0.

Para a avaliação dos parâmetros dendrométricos nos talhões foram instaladas dez parcelas experimentais, cada uma composta por dez árvores. Em cada parcela, em outubro-novembro de 2003, foram medidos: a circunferência à altura do peito (CAP); a distância média entre filas e covas nas filas; o número de falhas; número de árvores dominadas e de árvores mortas. Com esses dados, foram geradas as informações: densidade real de plantio; estado atual do povoamento; e distribuição diamétrica. Foram comparadas as distribuições diamétricas dos três sítios (TS, TM e TI) e avaliada a sua relação com o desenvolvimento dos plantios em cada posição da encosta. Foi aplicada a análise da variância, como condicionante para posterior aplicação do teste t, visando a testar semelhanças ou diferenças entre as médias dos tratamentos representados pelos tipos de solo nos sítios selecionados.

\section{RESULTADOS E DISCUSSÃO}

\section{Classes de solo e fertilidade}

Foram identificadas três classes de solos nas diversas posições da encosta, no TS o solo foi classificado como Argissolo Vermelho - Amarelo; no TM como Argissolo Amarelo; e Planossolo Háplico no TI (Tabela 1).

O Argissolo Vermelho-Amarelo, no terço superior da encosta, tem forte influência do material de origem, alteração de rochas gnáissicas, possuindo maior teor de argila em profundidade e maior Valor T e teor de carbono orgânico em superfície (Tabela 1), oferecendo um maior potencial para a produção agrícola. Já o Argissolo Amarelo, pela sua posição topográfica (TM), possui maior potencial de escoamento de água na superfície e em movimento lateral no perfil. O gradiente de textura aumenta a suscetibilidade à erosão, favorecendo a perda de nutrientes e de argila. O perfil apresenta cores mais amareladas, possivelmente pela maior alteração do material de origem, com menores valores de $\mathrm{S}$ e $\mathrm{T}$ que o Argissolo Vermelho-Amarelo. $\mathrm{O}$ Planossolo Háplico, no terço inferior da encosta, é formado com base em sedimentos coluviais e aluviais e é influenciado fortemente pela drenagem imperfeita. O solo tem como característica principal mudança textural abrupta do horizonte E para o Btg (Tabela 1), o que leva a um acúmulo de água e deficiência temporária de oxigênio no período chuvoso. O horizonte B possui coloração acinzentada e textura média, os horizontes A e E têm classe textural arenosa e baixo valor S, implicando em menor fertilidade natural. Por outro lado, o impedimento à drenagem condiciona a menor perda por lixiviação dos nutrientes adicionados pela adubação e o maior conteúdo de água em superfície para o plantio florestal.

Os perfis de solos apresentaram valores de $\mathrm{pH}$ na superfície que variaram de 4,2 a 5,5, indicando a 
acidez dos solos, com saturação por Al variável, mas sempre inferior a 50\%. Quanto aos percentuais de carbono orgânico, estes são ligeiramente mais elevados no Argissolo Vermelho-Amarelo, no horizonte superficial. O fato é observado para a soma de bases e para o Valor T. A maior fertilidade natural no perfil situado no TS é justificada pela maior influência do material de origem, fornecendo nutrientes pelo do intemperismo dos minerais primários, enquanto os demais perfis têm maior influência de sedimentos coluviais e aluviais já alterados. Em relação aos teores de fósforo, estes foram muito baixos em todos os horizontes e perfis de solos (Tabela 1).

TABELA 1: Atributos físicos e químicos dos perfis de solo na toposseqüência.

TABLE 1: Soil profile chemical and physical attributes in the toposequence.

\begin{tabular}{|c|c|c|c|c|c|c|c|c|c|}
\hline \multirow{3}{*}{$\begin{array}{l}\text { Perfil Horiz. / } \\
\text { prof. cm }\end{array}$} & \multirow{3}{*}{$\begin{array}{c}\mathrm{pH} \\
\mathrm{H}_{2} \mathrm{O}\end{array}$} & \multirow{3}{*}{$\begin{array}{l}\text { C org. } \\
\mathrm{g} \mathrm{kg}^{-1}\end{array}$} & \multicolumn{2}{|c|}{ Granulometria $^{1}$} & \multicolumn{4}{|c|}{ Complexo Sortivo } & \multirow{3}{*}{$\begin{array}{l}\mathrm{P} \text { assim. } \\
\mathrm{mg} \mathrm{kg}^{-1}\end{array}$} \\
\hline & & & AT & GF & Valor S & Valor T & Al Sat & $\mathrm{V}$ & \\
\hline & & & $\mathrm{g} \mathrm{kg}^{-1}$ & $\%$ & \multicolumn{2}{|c|}{$\mathrm{cmol}_{\mathrm{c}} \mathrm{kg}^{-1}$} & \multicolumn{2}{|l|}{$\%$} & \\
\hline \multicolumn{10}{|c|}{ TS - Argissolo Vermelho-Amarelo } \\
\hline $\mathrm{A}(0-11)$ & 5,5 & 8,0 & 115 & 65 & 3,30 & 8,62 & 3 & 38 & 1 \\
\hline $\mathrm{AB}(11-20)$ & 4,9 & 6,4 & 205 & 36 & 1,86 & 6,71 & 15 & 28 & 0 \\
\hline $\mathrm{BA}(20-38)$ & 5,0 & 5,4 & 235 & 40 & 1,75 & 6,19 & 9 & 28 & 0 \\
\hline $\mathrm{Bt}_{1}(38-79)$ & 5,1 & 2,9 & 549 & 98 & 1,49 & 5,52 & 11 & 27 & 0 \\
\hline $\mathrm{Bt}_{2}(79-111)$ & 5,2 & 3,2 & 488 & 97 & 1,74 & 5,61 & 3 & 31 & 0 \\
\hline $\mathrm{Bt}_{3}(111-132+)$ & 5,2 & 2,4 & 399 & 97 & 2,06 & 5,98 & 2 & 34 & 0 \\
\hline \multicolumn{10}{|c|}{ TM - Argissolo Amarelo } \\
\hline A $(0-32)$ & 4,5 & 6,1 & 160 & 47 & 2,10 & 6,48 & 16 & 32 & 8 \\
\hline AB (32-51) & 4,2 & 5,1 & 230 & 59 & 1,36 & 6,13 & 26 & 22 & 4 \\
\hline BA (51-79) & 4,6 & 5,1 & 295 & 60 & 0,99 & 5,54 & 33 & 18 & 5 \\
\hline Bt $(79-105+)$ & 4,5 & 3,0 & 425 & 80 & 0,56 & 4,73 & 44 & 12 & 3 \\
\hline \multicolumn{10}{|c|}{ TI - Planossolo Háplico } \\
\hline Ap (0-13) & 5,3 & 6,3 & 50 & 0 & 1,43 & 6,23 & 27 & 23 & 2 \\
\hline A (13-23) & 5,4 & 2,0 & 64 & 0 & 0,72 & 4,56 & 44 & 16 & 2 \\
\hline E (23-57) & 5,9 & 2,0 & 50 & 32 & 1,83 & 5,23 & 3 & 35 & 6 \\
\hline Btg $(57-80+)$ & 6,0 & 2,3 & 217 & 20 & 2,88 & 6,28 & 1 & 46 & 4 \\
\hline
\end{tabular}

Em que: $\mathrm{C}$ Org = Carbono orgânico; Valor S = Soma de bases; $\mathrm{V}$ = Saturação por bases; $\mathrm{P}$ assim. = Fósforo assimilável; Valor T = Capacidade de Troca Catiônica; Al Sat = Saturação por alumínio; AT = Argila Total; GF = Grau de Floculação; TS = Terço Superior; TM = Terço médio; TI = Terço Inferior.

Zimback et al. (1996) observaram maior correlação com a produtividade do Eucalyptus grandis e Eucalyptus urophylla, nos municípios de Mogi-Guaçú, Cochal e Aguaí, para os seguintes parâmetros físicos do horizonte A: densidade do solo, porosidade total e retenção de água a 0,03 MPa e 1,5 MPa. Ainda segundo Zimback et al. (1996) a soma de bases e a saturação por bases foram os fatores que apresentaram maior relação com o crescimento do Eucalyptus sp. Neste estudo, os valores S e V não mostraram relação com o desenvolvimento do Eucalyptus urophylla, possivelmente pelos baixos valores naturais, em todos os solos.

Os nutrientes no solo apresentam diferenças significativas entre os três sítios (TS, TM e TI), nas profundidades de $0-20$ e de $20-40 \mathrm{~cm}$ e para as amostragens entre linhas e entre plantas (Tabelas 2, 3, 4 e 5). $\mathrm{O}$ terço superior apresentou os maiores valores de $\mathrm{Ca}$ e $\mathrm{Mg}$, os menores teores de $\mathrm{Al}$ e níveis de $\mathrm{K}$ maiores que no terço inferior, nas amostragens entre plantas e entre linhas e em ambas as profundidades. Já o terço inferior apresentou diferenças significativas para a maior parte dos parâmetros químicos analisados, com os menores valores exceto para acidez e teor de Al. Esse resultado é explicado pela menor capacidade de retenção de cátions (Valor T) do solo, na camada superficial, no Planossolo, por causa da sua textura arenosa (Tabela 1).

Para o fósforo, foi observada diferença significativa apenas na camada de $0-20 \mathrm{~cm}$, na amostragem entre plantas, o que reflete a adubação em cobertura e a menor mobilidade desse elemento no perfil. Os teores de $\mathrm{P}$ foram maiores no TS e no TI que no TM. A maior acidez do solo $(\mathrm{H}+\mathrm{Al})$, no Argissolo Amarelo (TM), pode estar influenciando a disponibilidade do fósforo, com menores teores nesse solo (Tabela 2). 
Barros e Novais (1990) ressaltam a elevada tolerância do eucalipto à toxidez do alumínio; entretanto, segundo os autores, se o $\mathrm{Al}$ não causa toxidez diretamente para a cultura, ele influencia na absorção de nutrientes, com destaque para o fósforo.

TABELA 2: Análises químicas nas diferentes áreas, de $0-20 \mathrm{~cm}$ e na amostragem entre plantas.

TABLE 2: Chemical analysis in the different sites, at $0-20 \mathrm{~cm}$ depth for soil sampled between plants.

\begin{tabular}{c|c|c|c|c}
\hline \multirow{2}{*}{ Parâmetro } & Significância & \multicolumn{3}{|c}{ Valores Médios } \\
\cline { 3 - 5 } & ANOVA & TS & TM & TI \\
\hline $\mathrm{pH}$ & 0,00031 & $5,97 \mathrm{a}$ & $4,59 \mathrm{~b}$ & $4,23 \mathrm{~b}$ \\
$\mathrm{Ca}$ & 0,00000 & $2,27 \mathrm{a}$ & $1,00 \mathrm{~b}$ & $0,23 \mathrm{c}$ \\
$\mathrm{Mg}$ & 0,01394 & $3,23 \mathrm{a}$ & $1,03 \mathrm{~b}$ & $0,37 \mathrm{~b}$ \\
$\mathrm{Na}$ & 0,00012 & $0,07 \mathrm{a}$ & $0,05 \mathrm{~b}$ & $0,03 \mathrm{c}$ \\
$\mathrm{Al}$ & 0,00015 & $0,00 \mathrm{c}$ & $0,23 \mathrm{~b}$ & $0,47 \mathrm{a}$ \\
$\mathrm{H}+\mathrm{Al}$ & 0,00335 & $4,52 \mathrm{~b}$ & $6,63 \mathrm{a}$ & $4,57 \mathrm{~b}$ \\
$\mathrm{P}$ & 0,02974 & $29,64 \mathrm{a}$ & $4,74 \mathrm{~b}$ & $14,83 \mathrm{ab}$ \\
$\mathrm{K}$ & 0,00005 & $0,27 \mathrm{a}$ & $0,26 \mathrm{a}$ & $0,06 \mathrm{~b}$ \\
C. Org & 0,10257 & ns & ns & $\mathrm{ns}$ \\
\hline
\end{tabular}

Em que: TS = Terço superior; TM = Terço médio; TI = Terço inferior; Letras iguais na mesma linha não apresentam diferença significativa Tukey 5\%; ns = não-significativo.

Os teores de carbono orgânico no solo foram significativamente maiores no TS e no TM (Tabelas 3, 4 e 5). No TS, também os valores de pH são mais elevados, o que explica os menores teores de $\mathrm{Al}$ nesse sítio.

TABELA 3: Análises químicas nas diferentes áreas, de 20-40 cm e na amostragem entre plantas.

TABLE 3: Chemical analysis in the different sites, at 20-40 cm depth for soil sampled between plants.

\begin{tabular}{c|c|c|c|c}
\hline Parâmetro & Significância & \multicolumn{3}{|c}{ Valores Médios } \\
\cline { 3 - 5 } & ANOVA & TS & TM & TI \\
\hline $\mathrm{pH}$ & 0,00035 & $6,58 \mathrm{a}$ & $4,67 \mathrm{~b}$ & $4,33 \mathrm{~b}$ \\
$\mathrm{Ca}$ & 0,00000 & $2,10 \mathrm{a}$ & $0,77 \mathrm{~b}$ & $0,23 \mathrm{c}$ \\
$\mathrm{Mg}$ & 0,00165 & $1,80 \mathrm{a}$ & $0,73 \mathrm{~b}$ & $0,17 \mathrm{~b}$ \\
$\mathrm{Na}$ & 0,00487 & $0,05 \mathrm{a}$ & $0,04 \mathrm{a}$ & $0,02 \mathrm{~b}$ \\
$\mathrm{Al}$ & 0,00086 & $0,00 \mathrm{a}$ & $0,42 \mathrm{a}$ & $0,48 \mathrm{~b}$ \\
$\mathrm{H}+\mathrm{Al}$ & 0,00000 & $4,50 \mathrm{~b}$ & $6,50 \mathrm{a}$ & $4,57 \mathrm{~b}$ \\
$\mathrm{P}$ & 0,22176 & $\mathrm{~ns}$ & $\mathrm{~ns}$ & $\mathrm{~ns}$ \\
$\mathrm{~K}$ & 0,00017 & $0,12 \mathrm{a}$ & $0,13 \mathrm{a}$ & $0,04 \mathrm{~b}$ \\
$\mathrm{C}$ Org & 0,00015 & $0,53 \mathrm{~b}$ & $0,69 \mathrm{a}$ & $0,23 \mathrm{c}$ \\
\hline
\end{tabular}

Em que: TS = Terço superior; TM = Terço médio; $\mathrm{TI}=$ Terço inferior; Letras iguais na mesma linha não apresentam diferença significativa Tukey 5\%; ns = não-significativo.

TABELA 4: Análises químicas nas diferentes áreas, de 0-20cm, para amostragem entre linhas.

TABLE 4: Chemical analysis in the different areas, at 0-20cm depth for soil sampled between lines.

\begin{tabular}{c|c|c|c|c}
\hline Parâmetro & Significância & \multicolumn{3}{|c}{ Valores Médios } \\
\cline { 3 - 5 } & ANOVA & TS & TM & TI \\
\hline $\mathrm{pH}$ & 0,00085 & $5,35 \mathrm{a}$ & $4,71 \mathrm{~b}$ & $4,46 \mathrm{~b}$ \\
$\mathrm{Ca}$ & 0,00000 & $2,27 \mathrm{a}$ & $0,83 \mathrm{~b}$ & $0,27 \mathrm{c}$ \\
$\mathrm{Mg}$ & 0,02049 & $1,77 \mathrm{a}$ & $0,87 \mathrm{ab}$ & $0,53 \mathrm{~b}$ \\
$\mathrm{Na}$ & 0,03477 & $0,06 \mathrm{a}$ & $0,03 \mathrm{~b}$ & $0,04 \mathrm{ab}$ \\
$\mathrm{Al}$ & 0,01770 & $0,05 \mathrm{~b}$ & $0,38 \mathrm{a}$ & $0,33 \mathrm{a}$ \\
$\mathrm{H}+\mathrm{Al}$ & 0,00008 & $5,38 \mathrm{~b}$ & $7,07 \mathrm{a}$ & $4,43 \mathrm{c}$ \\
$\mathrm{P}$ & 0,07422 & $\mathrm{~ns}$ & $\mathrm{~ns}$ & $\mathrm{~ns}$ \\
$\mathrm{~K}$ & 0,00012 & $0,24 \mathrm{a}$ & $0,15 \mathrm{~b}$ & $0,07 \mathrm{~b}$ \\
$\mathrm{C}$. Org & 0,00032 & $1,04 \mathrm{a}$ & $0,82 \mathrm{~b}$ & $0,67 \mathrm{c}$ \\
\hline
\end{tabular}

Em que: TS = Terço superior; TM = Terço médio; TI = Terço inferior; Letras iguais na mesma linha não apresentam diferença significativa Tukey 5\%; ns = não-significativo. 
TABELA 5:Análises químicas nas diferentes áreas, de 20-40cm, para amostragem entre linhas.

TABLE 5: Chemical analysis in the different sites, at 20-40cm depth for soil sampled between lines.

\begin{tabular}{c|c|c|c|c}
\hline \multirow{2}{*}{ Parâmetro } & Significância & \multicolumn{3}{|c}{ Valores Médios } \\
\cline { 3 - 5 } & ANOVA & TS & TM & TI \\
\hline $\mathrm{pH}$ & 0,00052 & $5,54 \mathrm{a}$ & $4,53 \mathrm{~b}$ & $4,53 \mathrm{~b}$ \\
$\mathrm{Ca}$ & 0,00003 & $1,87 \mathrm{a}$ & $0,87 \mathrm{~b}$ & $0,20 \mathrm{c}$ \\
$\mathrm{Mg}$ & 0,02086 & $1,70 \mathrm{a}$ & $0,87 \mathrm{ab}$ & $0,23 \mathrm{~b}$ \\
$\mathrm{Na}$ & 0,00538 & $0,05 \mathrm{a}$ & $0,03 \mathrm{~b}$ & $0,03 \mathrm{~b}$ \\
$\mathrm{Al}$ & 0,00040 & $0,00 \mathrm{~b}$ & $0,40 \mathrm{a}$ & $0,42 \mathrm{a}$ \\
$\mathrm{H}+\mathrm{Al}$ & 0,00002 & $4,77 \mathrm{~b}$ & $6,75 \mathrm{a}$ & $4,03 \mathrm{c}$ \\
$\mathrm{P}$ & 0,02996 & $0,94 \mathrm{ab}$ & $0,00 \mathrm{~b}$ & $5,72 \mathrm{a}$ \\
$\mathrm{K}$ & 0,00010 & $0,13 \mathrm{a}$ & $0,10 \mathrm{a}$ & $0,05 \mathrm{c}$ \\
$\mathrm{C}$. Org & 0,02286 & $0,68 \mathrm{a}$ & $0,69 \mathrm{a}$ & $0,43 \mathrm{~b}$ \\
\hline
\end{tabular}

Em que: TS = Terço superior; TM = Terço médio; TI = Terço inferior; Letras iguais na mesma linha não apresentam diferença significativa Tukey 5\%; ns = não-significativo.

Low (1997) estudou a relação entre parâmetros físicos e químicos do solo com o índice de produção do Eucalyptus grandis, aos 20 anos, em Mpumalanga Escarpment, África do Sul. O autor verificou que o conteúdo de água e o teor de carbono orgânico no solo foram as variáveis que melhor se correlacionaram com a produtividade do Eucalyptus grandis. Segundo Sgarbi (2002), os teores de carbono no solo explicam, em grande parte, as variações na produtividade, sendo fundamental a sua consideração nos levantamentos nutricionais realizados em plantios de Eucalyptus sp. Já no estudo de Mushaka (1998), correlacionando parâmetros químicos do solo e a produtividade do Eucalyptus camaldulensis, com idade entre 1 e 10 anos, no Zimbabwe, África do Sul, não foram observadas correlações significativas para o $\mathrm{pH}$, teores de matéria orgânica, ou níveis de fósforo e potássio.

\section{Parâmetros dendrométricos}

Em relação aos parâmetros dendrométricos (Tabela 6), existem diferenças entre as áreas médias por cova nas parcelas experimentais nos três sítios. No TS os valores medidos podem ser considerados adequados quando comparados ao planejado na implantação do povoamento ( $10 \mathrm{~m}^{2}$ por cova). Já no TI foi observado um desvio de $8,7 \%$ na área média por cova em relação ao planejado, resultando em um povoamento mais denso que os demais. Entretanto, ao se considerar o número de árvores vivas, as parcelas experimentais no TM e TI apresentam maior número de falhas que no TS. Portanto, o povoamento no terço superior apresentou maior densidade de árvores vivas.

TABELA 6: Parâmetros dendrométricos do povoamento de eucalipto nas parcelas experimentais nas diferentes posições da encosta.

TABLE 6: Dendrometric parameters of the eucalypt sites in the experimental plots, in the different slope positions.

\begin{tabular}{l|c|c|c}
\hline \multirow{2}{*}{ Parâmetros Dendrométricos } & \multicolumn{3}{c}{ Medições nas Parcelas Experimentais } \\
\cline { 2 - 4 } & TS & TM & TI \\
\hline Espaçamento entre linhas (m) & 2,00 & 1,99 & 1,93 \\
Espaçamento entre covas (m) & 5,01 & 4,93 & 4,74 \\
Área média por cova $\left(\mathrm{m}^{2}\right)$ & 10,01 & 9,81 & 9,13 \\
Número de covas da área experimental & 100 & 100 & 100 \\
Número de falhas & 2 & 18 & 17 \\
Número de mortas & 1 & 0 & 0 \\
Número de dominadas & 1 & 0 & 0 \\
Número de bifurcadas & 0 & 1 & $3(\mathrm{a})$ \\
Número de árvores vivas & 96 & 82 & 83 \\
Número de fustes (b) & 96 & 83 & 88 \\
Área basal por hectare $\left(\mathrm{m}^{2}\right)$ & 4,11 & 2,81 & 4,64 \\
\hline
\end{tabular}

Em que: TS = Terço superior; TM = Terço médio; TI = Terço inferior; (a) = uma bifurcação e duas árvores com 3 fustes, (b) = incluem as bifurcações. 
Quanto à distribuição das freqüências absolutas dos diâmetros das árvores nas três áreas experimentais (Figura 1), foi observado que as distribuições referentes às áreas TI e TS, apesar de assimetrias ligeiramente diferentes, apresentam amplitudes semelhantes, diferindo apenas na freqüência da classe central da distribuição, em função do número de árvores vivas diferente entre elas. O padrão de distribuição das classes de diâmetros em TM evidencia o menor desenvolvimento das árvores, estando a curva que representa o histograma à esquerda das demais.

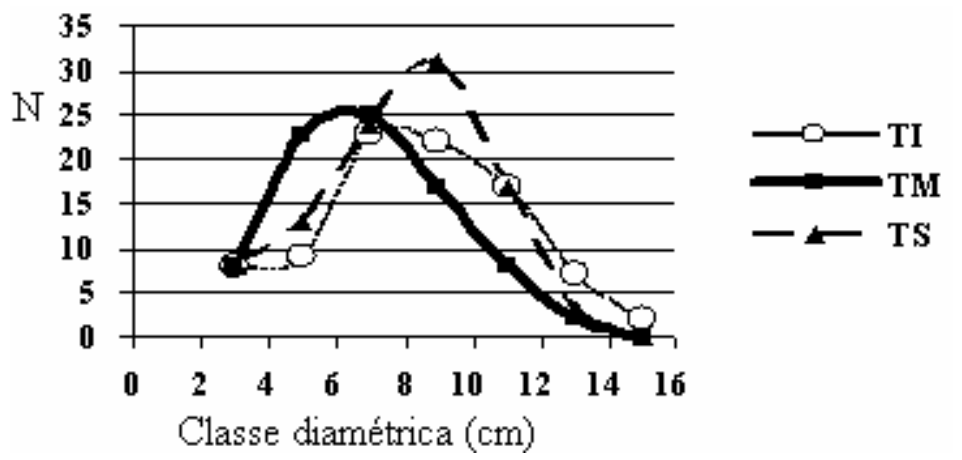

FIGURA 1: Freqüência da distribuição absoluta das classes de diâmetro (cm), nas parcelas experimentais nos terços superior (TS), médio (TM) e inferior (TI) da encosta.

FIGURE 1: Frequency of absolute distribution of diameter classes $(\mathrm{cm})$, in the experimental plots in the summit (TS), back slope (TM) and foot slope (TI) positions.

Os valores de diâmetro modal das árvores (Tabela 7) mostram que as árvores mais grossas, individualmente, ocorrem no terço inferior da encosta. Nessa posição, também são observados os maiores valores de área basal por hectare (Tabela 6), seguida pelo TS.

TABELA 7: Valores dos diâmetros das árvores nas parcelas experimentais, nas diferentes posições da encosta.

TABLE 7: Values of tree diameter in the experimental plots, in the different slope positions.

\begin{tabular}{l|c|c|c}
\hline Índices Calculados & TS & TM & TI \\
\hline Média aritmética dos diâmetros & 7,30 & 6,06 & 6,96 \\
Diâmetro médio $(\mathrm{cm})$ & 7,83 & 6,50 & 7,38 \\
Diâmetro modal $(\mathrm{cm})$ & 6,00 & 6,00 & 8,00 \\
\hline
\end{tabular}

Em que: $\mathrm{TS}=$ Terço superior; $\mathrm{TM}=$ Terço médio; $\mathrm{TI}=$ Terço inferior.

Segundo Spurr e Barnes (1980), dentro de um estrato climático, variações locais de topografia podem levar à formação de padrões de crescimento diferente. Barros e Novais (1990) afirmam que é necessário um melhor conhecimento das espécies e ou procedências de eucalipto relacionando-as com características edafoambientais. As variações nos parâmetros dendrométricos, com a posição da encosta e o tipo de solo, evidenciam a influência dos atributos edáficos na produtividade dos povoamentos de eucalipto.

Foram observadas diferenças significativas entre os sítios nas diversas posições da encosta, quanto aos teores de nutrientes do solo e outros atributos químicos, além de classes de solo distintas, que se refletiram em variações nos parâmetros dendrométricos. Os sítios onde os atributos edafoambientais mais influenciaram positivamente os parâmetros dendrométricos do Eucalyptus urophylla foram o TI e o TS. No terço inferior da encosta, em solo Planossolo, os parâmetros dendrométricos mostram-se favoráveis, possivelmente, pelas condições de maior disponibilidade hídrica. Já o TS possui maior nível de fertilidade natural e oferta de nutrientes que os demais sítios, ainda que a sua posição topográfica favoreça maior infiltração e menor disponibilidade de água no solo nos períodos secos.

Santana (1986) verificou que Eucalyptus saligina apresentou, na região do Médio Rio Doce, em Minas Gerais, maior produtividade nos solos distróficos (Latossolos) dos topos das elevações, em relação aos solos mais férteis das encostas e das baixadas da região (Argissolos). Tal fato parece ser explicado pela elevada densidade dos solos das partes mais baixas da paisagem, o que impede o crescimento do sistema radicular em profundidade, fato crítico em uma região de período seco marcado. Além disso, as baixadas da região, apesar de férteis ( $\mathrm{V}>80 \%$ ), apresentam baixa permeabilidade. Durante o período chuvoso, tornam-se 
encharcadas e, nos meses secos, os solos tornam-se extremamente endurecidos. Nos povoamentos de eucalipto estudados, a textura arenosa dos Planossolos, até a profundidade de $57 \mathrm{~cm}$ (Tabela 1), e o fato de que a área foi artificialmente drenada por volta do ano de 1960, foram favoráveis ao desenvolvimento dos plantios de eucalipto.

O sítio onde se observou a influência mais negativa dos atributos edafoambientais nos parâmetros dendrométricos foi o do terço médio, de solo Argissolo Amarelo. Sua posição topográfica e natureza do material de origem mais intemperizado e com baixa fertilidade natural contribuem para maior intensidade de perdas de água e nutrientes (Silva et al., 2001), resultando em baixa homogeneidade do sítio e potencial de produtividade inferior, quando comparado aos demais.

\section{CONCLUSÕES}

Os talhões apresentaram diferentes classes de solos de acordo com a posição topográfica, quais sejam Argissolo Vermelho-Amarelo, Argissolo Amarelo e Planossolo Háplico, e as propriedades inerentes à gênese desses solos influenciaram nos parâmetros dendrométricos medidos neste estudo, evidenciando a influência do tipo de solo no potencial de produtividade dos povoamentos de eucalipto.

Os teores de Ca, Mg, K, e de carbono orgânico mostraram variação significativa com a posição topográfica, sendo os maiores teores geralmente observados no terço superior da encosta. Já o $\mathrm{Al}$ apresentou maiores valores no terço médio (TM) e terço inferior (TI).

Quanto aos parâmetros dendrométricos, o número de falhas foi maior nas parcelas experimentais nos sítios no TM e TI. Enquanto, o povoamento no terço superior (TS) apresentou maior densidade de árvores vivas. Já os valores de diâmetro modal mostram árvores mais grossas, individualmente, no terço inferior da encosta. Os maiores valores de área basal foram observados em TS e TI, respectivamente, 4,11 e $4,64 \mathrm{~m}^{2} \mathrm{ha}^{-1}$.

\section{REFERÊNCIAS BIBLIOGRÁFICAS}

BARROS, N. F; NOVAIS, R.F. Relação solo-eucalipto. Viçosa: Folha de Viçosa, 1990. 330p.

BELLOTE, A.F.J.; FERREIRA, C.A. Nutrientes minerais e crescimento de árvores adubadas de Eucalyptus grandis na região do cerrado no Estado de São Paulo. Boletim de Pesquisa Florestal, n.26/27, p. 17-28, 1993.

CORRÊA NETO, T.C. Atributos edafoambientais condicionadores da capacidade produtiva de plantios de eucalipto no Campus da UFRRJ. 2004. 64f. Dissertação (Mestrado) - Universidade Federal Rural do Rio de Janeiro, Seropédica. 2004.

EMPRESA BRASILEIRA DE PESQUISA AGROPECUÁRIA. Manual de métodos de análise de solo. Rio de Janeiro: Embrapa Solos, 1997. 212p.

EMPRESA BRASILEIRA DE PESQUISA AGROPECUÁRIA. Sistema Brasileiro de Classificação de Solos. Rio de Janeiro: Embrapa Solos, 1999. 412p.

FERREIRA, C.A; COUTO, H.T.Z. Influência de variáveis ambientais no crescimento de espécies/ procedências de Eucalyptus spp. nos estados de Minas Gerais e Espírito Santo. Boletim de Pesquisa Florestal, n. 3, p. 9-25, 1981.

HOSOKAWA, R.T. Introdução ao manejo e economia de florestas. Curitiba: Ed. UFPR, 1988. 162p.

LEMOS, R.C.; SANTOS, R.D. dos. Manual de descrição e coleta de solo no campo. 3.ed. Campinas: Sociedade Brasileira de Ciência do Solo, 1996. 83p.

LOW, J.H. A site-growth study of Eucalyptus grandis in the Mpumalanga Escarpment area. Southern African Forestry Journal, n.180, p. 1-13, 1997.

MACHADO, S.A.; FIGUEIREDO FILHO, A. Dendrometria. Curitiba: Editora UFPR, 2003. 309p.

MUSHAKA, A. Relationship between growth, mineral nutrition and site factors for Eucalyptus camaldulensis (Dehnh) planted in some communal areas of Zimbabwe. Southern African Forestry Journal, n.183, p. 59-65, 1998.

SANTANA, J.A.S. Efeitos das propriedades dos solos na produtividade de duas espécies de eucalipto na região do médio Rio Doce, MG. 1986. 117f. Dissertação (Mestrado) - Universidade Federal de Viçosa, Viçosa, 1986.

SGARBI, F. Produtividade do Eucalyptus sp. em função do estado nutricional e da fertilidade do solo em diferentes regiões do Estado de São Paulo. 2002. 101f. Dissertação (Mestrado) - ESALQ/USP, Piracicaba, 2002.

SILVA, M.B.; ANJOS, L.H.C. dos; NASCIMENTO, R.A. de M. Estudo de toposseqüência da Baixada Litorânea 
Fluminense: efeitos do material de origem e posição topográfica. R. Bras. Ci. Solo, v. 25, p. 967-978, 2001.

SPURR, S.H.; BARNES, B.V. Forest ecology. New York: JohnWiley, 1980. 687p.

ZAIA, F.C.; GAMA-RODRIGUES, A.C. Ciclagem e balanço de nutrientes em povoamentos de eucalipto na região Norte Fluminense. R. Bras. Ci. Solo, v. 28, p. 843-852, 2004.

ZIMBACK, C.R.L.; MORAES, M.H.; LIMA, S.L de; CARVALHO, A.M. de. Correlações entre propriedades químicas e físicas dos solos com a produtividade de Eucalyptus spp em Latossolos Vermelho-Amarelos em São Paulo. In: CONGRESSO LATINO AMERICANO DE CIÊNCIA DO SOLO, 12., 1996, Águas de Lindóia. Anais... 1996. CDROM. 